\title{
Large Area Free-Standing Single Crystalline Films of p-Quinquephenyl: Growth, Structure and Photoluminescence Properties
}

\author{
Valery A. Postnikov ${ }^{1, * \mathbb{D}}$, Nataliya I. Sorokina ${ }^{1}$, Maria S. Lyasnikova ${ }^{1, *}$, Artem A. Kulishov ${ }^{1}$, \\ Alexey E. Voloshin ${ }^{1}$, Oleg V. Borshchev ${ }^{2}{ }^{-}$, Nikolay M. Surin ${ }^{2}$, Evgeniya A. Svidchenko ${ }^{2}$ and \\ Sergey A. Ponomarenko ${ }^{2}$ \\ 1 FSRC “Crystallography and Photonics" of Russian Academy of Sciences, Shubnikov Institute of \\ Crystallography, Moscow 119333, Russia; nsor@crys.ras.ru (N.I.S.); adakyla1255@gmail.com (A.A.K.); \\ labsol@yandex.ru (A.E.V.) \\ 2 Enikolopov Institute of Synthetic Polymer Materials of Russian Academy of Sciences, \\ Moscow 117393, Russia; borshchev@ispm.ru (O.V.B.); niksurin@yandex.ru (N.M.S.); \\ evgensv@yandex.ru (E.A.S.); ponomarenko@ispm.ru (S.A.P.) \\ * Correspondence: postva@yandex.ru (V.A.P.); mlyasnikova@yandex.ru (M.S.L.); \\ Tel.: +7-(985)-749-69-24 (V.A.P.)
}

Received: 23 March 2020; Accepted: 23 April 2020; Published: 1 May 2020

\begin{abstract}
Studies of the growth of large-area free-standing single-crystalline films of p-quinquephenyl are presented. High-quality crystals were grown by slow cooling of a hot chlorobenzene solution. Worse quality large-area free-standing single crystals of p-quinquephenyl were also grown by using physical vapor transport and used for comparison. The crystal structure of p-quinquephenyl at $293 \mathrm{~K}$ and $85 \mathrm{~K}$ was refined by single-crystal $\mathrm{X}$-ray diffraction. The optical absorption and photoluminescence spectra of solutions and crystalline films were obtained and analyzed; a positive solvatochromic effect was detected.
\end{abstract}

Keywords: p-quinquephenyl; single crystals; crystal growth; solutions; physical vapor transport; SCXRD; crystal structure; absorption and photoluminescence spectra; solvatochromism

\section{Introduction}

Linear $\pi$-conjugated oligomers are of great interest for organic optoelectronics as substances on the basis of which it is possible to grow single-crystal films or plates with a minimum number of defects using growth methods from solutions or by vapor deposition. This makes it possible to achieve high electrical and electro-optical characteristics in devices [1-8]. P-quinquephenyl, consisting of five conjugated phenyl rings (5P), belongs to a family of linear oligophenyls, which are known as highly stable blue emitters with a high external photoluminescence quantum yield (PLQY) in the crystals [9].

$5 \mathrm{P}$ crystals are still understudied in terms of their electrical properties. In particular, there is a publication on the study of hole transport mobility using the field-effect transistor method in a 5P polycrystalline film [10]. In the other recent work [11], it was reported that potassium-doped p-quinquephenyl crystals exhibit superconducting properties at temperatures below $7.3 \mathrm{~K}$.

As far as growth of $5 \mathrm{P}$ crystals is concerned, the literature mainly contains information on the growth of thin polycrystalline films on the substrates by thermal vacuum deposition [12-14], while there is no information on the growth of large single-crystalline 5P films. To obtain single crystals, growth methods from solutions are the most attractive because of their simplicity and efficiency, but, in this case, solubility of the oligomer for the crystal growth is a key factor. At room temperature, the solubility of p-quinquephenyl is very low $(\mathrm{C}<0.1 \mathrm{~g} / \mathrm{L}$ [15] $)$ and, therefore, growth of relatively large 
crystals from solutions under these conditions is hardly possible. One of the approaches to increase solubility of the oligomer in order to improve its crystal growth characteristics is to add branched terminal substituents into the molecular structure. However, this approach will naturally lead to a change in the crystal structure, which will be more friable, and, accordingly, to a greater or lesser extent, will affect the electrical and optical properties of the crystals [16-20]. Without changing the chemical structure, it is possible to significantly improve the solubility of the oligomer due to a substantial increase in the solution temperature.

This work presents the results of large-area film-like free-standing single crystals of p-quinquephenyl growth by slow cooling of a hot chlorobenzene solution. To obtain 5P single crystals, we have also used the method of physical vapor transport, which has been proven to crystallize low-soluble conjugated oligomers [21-23]. Using single-crystal X-ray diffraction, the crystal structures were refined at $85 \mathrm{~K}$ and $295 \mathrm{~K}$. An analysis of the optical absorption and photoluminescence spectra in 5P solutions and crystalline films is also reported.

\section{Experimental Section}

\subsection{Materials}

The 5P was synthesized according to the procedure described earlier [24]. Chlorobenzene (analytical grade) was bought from EKOS-1 (Moscow, Russia). Hexane (analytical grade) and tetrahydrofuran (THF) (analytical grade) were obtained from Sigma-Aldrich (Moscow, Russia). Nitrogen (purity 99.9999\%) was purchased from NII KM Ltd. (Moscow, Russia).

\subsection{Crystal Growth}

A relatively higher solubility of $5 \mathrm{P}$ can be achieved by significant heating of its solution. In this regard, the method of slow isochoric cooling of the pre-heated 5P solution was applied. Chlorobenzene was used as a solvent. The $5 \mathrm{P}$ solution with an initial concentration of $0.4 \mathrm{~g} / \mathrm{L}$ was preliminarily prepared in $20 \mathrm{~mL}$ glass vials within $2 \mathrm{~h}$ at $50-60^{\circ} \mathrm{C}$ using an ultrasonic bath PCB-2835-05 (Moscow, Russia). As a result of this treatment, the substance could not be completely dissolved. Therefore, the solution was heated to $120^{\circ} \mathrm{C}$ and kept at this temperature for about $2 \mathrm{~h}$ until the microfine crystalline precipitate at the bottom visually completely disappeared. After that the solution was slowly cooled down at the linear rate of $0.1 \mathrm{~K} / \mathrm{h}$ within 32 days, until $43^{\circ} \mathrm{C}$ was reached. Heating, isothermal aging and slow cooling of the solution were carried out in a growth resistance furnace of the original design with the use of a Thermodat-16K6 thermo-controller (Thermodat, Permian, Russia). To stabilize the temperature of the solution inside the furnace, a brass cup holder was made with a side wall thickness of $2 \mathrm{~mm}$ and a bottom thickness of $5.5 \mathrm{~mm}$. At the bottom of the cup holder, there was a small window to observe the degree of dissolution under UV light.

The method of physical vapor transport (PVT) [21] was also applied for the growth of 5P crystals. The inner diameter of the growth quartz tube was $19 \mathrm{~mm}$. Nitrogen was used for purging the growth tube. Control of the inert gas flow in the growth pipe in low-intensity mode $(\sim 0.2 \mathrm{~L} / \mathrm{h})$ was carried out using a flow-meter controller RRG-12 with an external control interface RRG-K (Eltochpribor Ltd., Moscow, Russia). Crystal growth was carried out at the temperature of $310-315^{\circ} \mathrm{C}$ at the source of the substance over 2.5-3 days (Figure 1). Figure 1 shows a temperature profile inside the growth tube, which specifies positions of the substance source and the crystal growth zones. The surface inside the growth quartz tube was coaxially closed with $20-\mu \mathrm{m}$ thick aluminum foil for the convenience of subsequent extraction of the crystalline films. Large 5P crystals were formed almost without any adhesion to the surface of the aluminum foil, so that they could be easily removed without violating their integrity. 


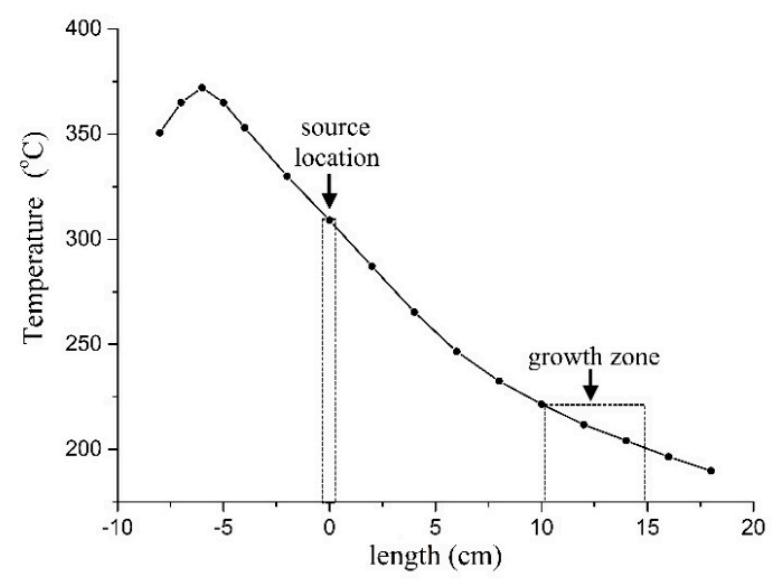

Figure 1. Temperature profile inside the quartz growth tube with the specified positions of the substance source and the p-quinquephenyl crystals growth zone.

\subsection{Optical and Laser Confocal Microscopy}

The surface morphology and the crystal habit were investigated using an Olympus BX61 (Tokyo, Japan) optical microscope and an Olympus LEXT OLS 3100 (Tokyo, Japan) laser scanning confocal microscope. The thickness of crystalline films was determined on the Olympus LEXT OLS 3100 microscope in scanning confocal mode.

\subsection{X-Ray Diffraction}

X-ray intensity data sets for $5 \mathrm{P}$ solution-grown single crystals of no more than $0.5 \mathrm{~mm}$ in size were collected at room temperature and at $85 \mathrm{~K}$ on an Xcalibur Eos S2 X-ray diffractometer (Rigaku Oxford Diffraction, Abingdon, Oxfordshire, UK) (Mo K $\alpha$ radiation). The experimental data were processed using the CrysAlis program (Rigaku Oxford Diffraction, Abingdon, Oxfordshire, UK) [25]. The rest of the calculations were performed using a crystallographic software package JANA2006 (Praha, Czech Republic) [26]. A model of the atomic structure of a crystal consisting of carbon atoms was obtained by the charge flipping method, using the SUPERFLIP program [27], which is part of the JANA2006 program package. The structural parameters were refined using the least squares method in the full-matrix version.

The structure of 5P vapor-grown crystals, because of their low morphological quality, was studied using a Miniflex 600 powder X-ray diffractometer (Rigaku, Japan) with $\mathrm{Cu} \mathrm{K} \alpha$ radiation $(\lambda=1.54178 \AA$, recording speed of $2 \mathrm{deg} / \mathrm{min}$ ).

\subsection{Absorption and Photoluminescence Spectra}

The absorption spectra of 5P solutions were measured on a Shimadzu UV-2501PC spectrophotometer (Kyoto, Japan) in quartz cuvettes with an optical path length of $10 \mathrm{~mm}$. The photoluminescence (PL) spectra of 5P solutions and large free-standing single-crystalline films were recorded on an ALS-1M spectrofluorimeter with two MUM-5 monochromators and a quantum counter (developed at the Institute of Synthetic Polymer Materials, Russian Academy of Sciences, Moscow, Russia) [28] and on a spectrophotometer-fluorimeter SFF-2 FLUORAN (VNIIOFI, Moscow, Russia). Standard fluorescence cuvettes made of fused quartz $\left(10 \times 10 \mathrm{~mm}^{2}\right)$ were used to measure the PL spectra of the solutions. The photoluminescence quantum yield (PLQY) of dilute solutions $\left(\mathrm{A}_{\max }<0.1\right)$ was measured relative to a solution of 1,4-bis-2-(5-phenyloxazolyl)-benzene in cyclohexane $\left(\phi_{\mathrm{QYPL}}=0.93\right.$ [29]). To obtain PL spectra of p-quinquephenyl crystals, the free-standing single-crystalline films were placed between two plates of fused quartz. During the measurements on ALS-01M, the plates were placed on a Teflon integrating sphere installed in the cuvette compartment. During the measurements on SFF-2, the plates were set at an angle of $45^{\circ}$ to the exciting radiation so that the reflected radiation was directed in the opposite direction from the input slit of the recording monochromator. The PLQY of p-quinquephenyl 
single crystals was measured in two ways: (1) in the integrating sphere when luminescence was excited by UVLED255 led radiation $(260 \mathrm{~nm}, 100 \mathrm{~mW})$; (2) by comparison with the luminescence intensity of a tetraphenylbutadiene polycrystalline film with a known quantum yield $(0.9)[30,31]$.

\section{Results}

\subsection{Crystal Growth and Morphology}

\subsubsection{Growth from Solution}

Several growth experiments were carried out, at the end of which large-area free-standing single-crystalline films of $5 \mathrm{P}$ were found at the bottom of the growth vial. The dimensions of the largest crystals were limited by the diameter of the vials and thus reached 15-20 mm in length (Video S1 in Supplementary Materials). During extraction from the solution with the help of a metal mesh, large, free-standing single crystals were fragmented. As an example, Figure 2a presents a number of large crystal fragments under the UV light. Individual entire crystals with the regular shape in the form of a parallelogram with the internal angles of $69^{\circ}-70^{\circ}$ and $110^{\circ}-111^{\circ}$, having small sizes, were found (Figure $2 b, c)$. For example, Figure $2 b$ shows an image (Olympus BX61) of an about $6.5-\mu m$ thick single crystal of $5 \mathrm{P}$ in the transmitted light with the crossed polarizers. As can be seen from the image, the surface of this crystal is homogeneous and relatively smooth. The crystal shown in Figure $2 \mathrm{c}$ has a more convex shape. With a length of the largest side of $1.65 \mathrm{~mm}$, its average thickness is about $120 \mu \mathrm{m}$. In this case, the surface of the well-developed crystal face is more heterogeneous, and there are hills up to $9 \mu \mathrm{m}$ high on the top of it. These growth formations are largely elongated along the crystallographic growth directions and in a number of places form cross-shaped figures (Figure 2c-f). For example, the higher magnification images in Figure 2d,e (Olympus LEXT OLS 4100) show sections of the crystal surface with the elongated hills, which are marked by arrows " 1 " and " 2 " in Figure $2 c$, respectively. The surface morphology developed was observed on the almost all large single crystals. The elongated growths often formed a dense dendritic grid on the crystal surface, as, in particular, can be seen in the reflected light shown in Figure $2 \mathrm{f}$ in the mode of deep phase contrast (Olympus BX61). A similar phenomenon was observed earlier when studying the morphology of of p-terphenyl and p-quaterphenyl crystals grown from solutions [18,32].
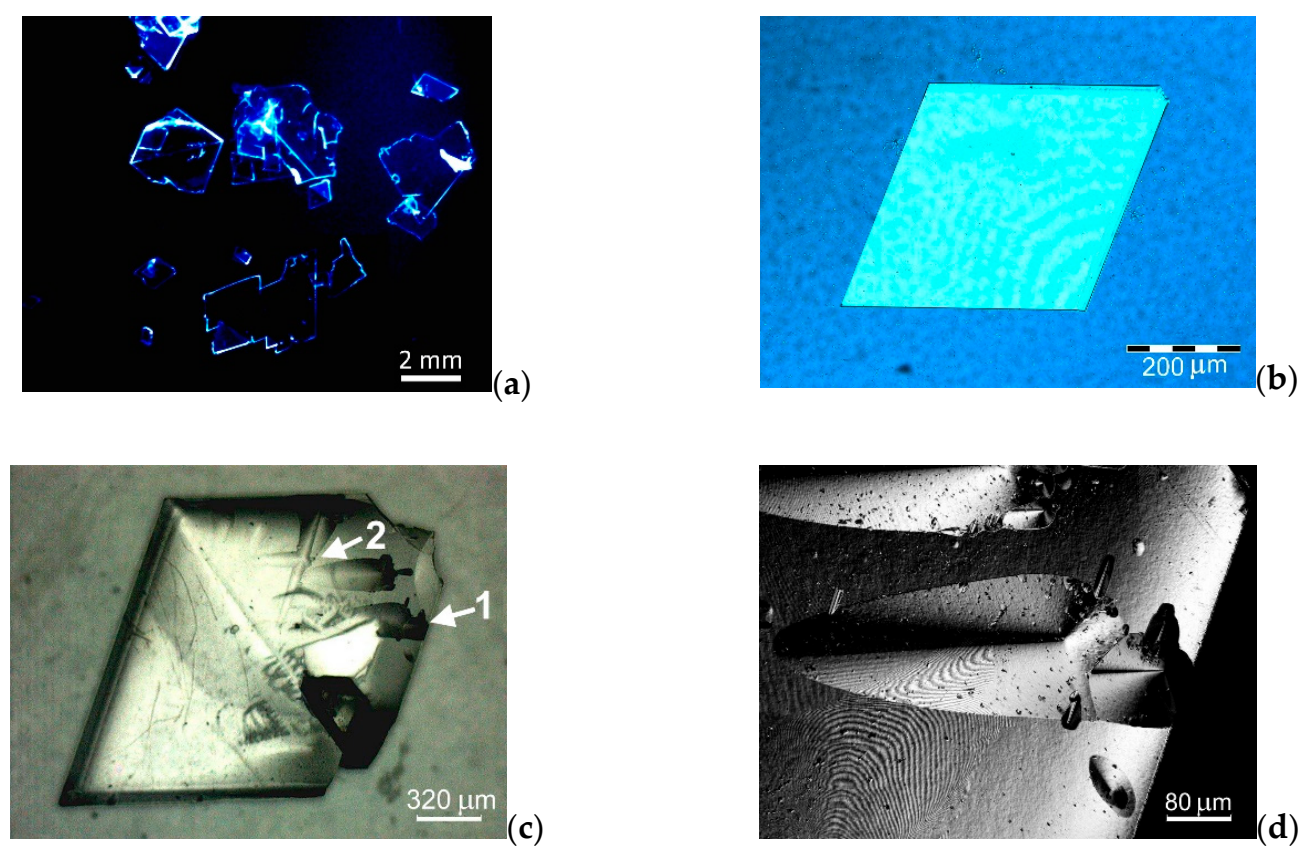

Figure 2. Cont. 

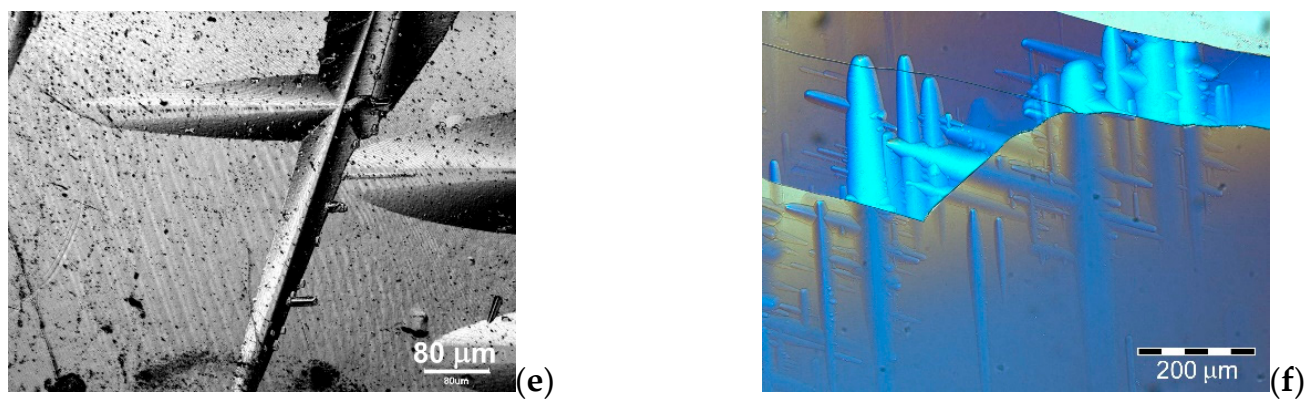

Figure 2. p-Quinquephenyl crystals grown from solution: (a) a group of crystals under the UV light; (b) the optical image of a thin single crystal in the transmitted light with the crossed polarizers; (c) the optical image of a thickened single crystal in the reflected light, enlarged confocal images (in scanning mode) of the crystal section marked by arrows " 1 " (d) and " 2 " (e) in Figure (c); (f) the optical image in the reflected light (in deep phase contrast mode) of the dendritic growths network on the crystal surface.

\subsubsection{Growth by PVT Method}

5P crystals grown by the PVT method have a different morphology. In this case, relatively large-area free-standing single-crystalline films up to $8 \mathrm{~mm}$ long, but much thinner than those obtained from the solution, were grown for about 3 days (Figure $3 a, b)$. Compared to the crystals grown from solutions, the lateral sides of the vapor-grown crystals have an irregular rounded shape (Figure $3 a, b$ ), which indicates a nonuniform flow of the substance to the surface during the growth process. This is apparently associated with a significant temperature drop within the film length $(\sim 4 \mathrm{~K} / \mathrm{cm})$, which causes unequal growth processes on its surface (Figure 1). The crystal shown in Figure 3a has an average thickness at the periphery of about $1.6 \mu \mathrm{m}$. There are many dislocation hills up to $1 \mu \mathrm{m}$ high on the crystal surface (Figure 3c). For example, Figure 3d shows a confocal image of the top of a dislocation hill, which is a multiturn spiral of growth. The crystal shown in Figure $3 \mathrm{~b}$ has a thickness of about $300-400 \mathrm{~nm}$ and has a smoother surface morphology.
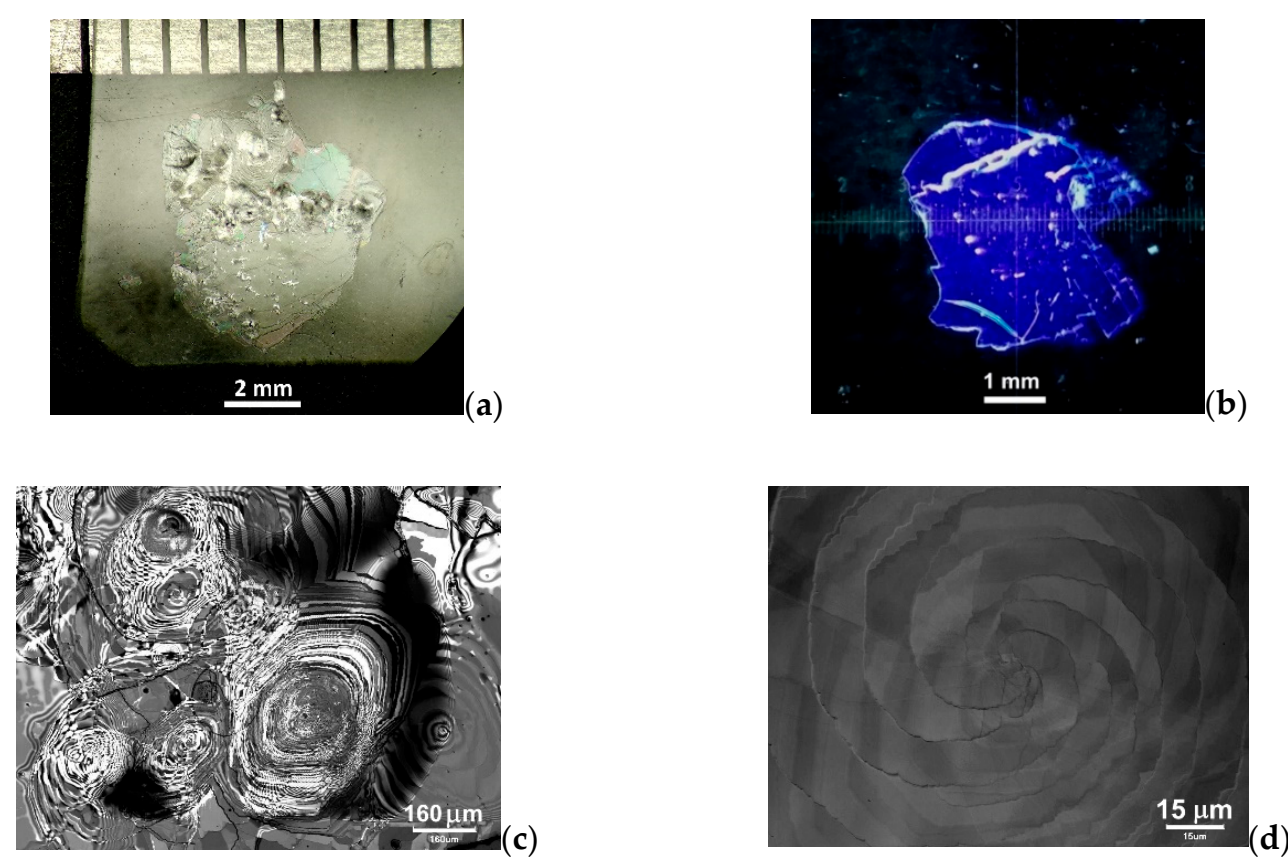

Figure 3. p-Quinquephenyl crystals grown by the PVT method: $(\mathbf{a}, \mathbf{b})$ photographic images of the crystals laminated on a glass substrate ((b)-under the UV light of $365 \mathrm{~nm})$; (c) the confocal image (scanning mode) of the surface area with a number of dislocation growth hills; (d) the confocal image (scanning mode) of the apex of the multiturn dislocation spiral. 


\subsection{Crystal Structure}

The main crystallographic parameters and the results of the structure refinement at temperatures of $293 \mathrm{~K}$ and $85 \mathrm{~K}$ of a 5P solution-grown single crystal are shown in Table 1 (CIF S1 and CIF S2 in Supplementary Materials).

Table 1. Crystallographic characteristics, experimental data and structure refinement parameters of p-quinquephenyl.

\begin{tabular}{ccc}
\hline Formula & & $\mathrm{C}_{30} \mathrm{H}_{22}$ \\
Temperature $(\mathrm{K})$ & 293 & 85 \\
Crystal system & monoclinic & triclinic \\
Space group & $\mathrm{P} 2{ }_{1} / \mathrm{c}$ & $\mathrm{P}-1$ \\
$a(\AA)$ & $22.059(1)$ & $22.042(1)$ \\
$b(\AA)$ & $5.579(1)$ & $11.018(1)$ \\
$c(\AA)$ & $8.070(1)$ & $15.970(1)$ \\
$\alpha\left(^{\circ}\right)$ & 90.0 & $90.049(6)$ \\
$\beta\left(^{\circ}\right)$ & $97.989(7)$ & $98.203(5)$ \\
$\gamma\left({ }^{\circ}\right)$ & 90.0 & $90.425(5)$ \\
$V_{o}\left(\AA^{3}\right)$ & $983.55(6)$ & $3838.6(1)$ \\
$Z$ & 2 & 8 \\
$D_{\text {calc }}\left(\mathrm{g} / \mathrm{cm}^{3}\right)$ & 1.292 & 1.324 \\
No. of measured, independent and & $20,654,5233,1648$ & $84,275,37,255,5057$ \\
observed $[I>3 \sigma(I)]$ reflections & 180 & 1081 \\
No. of refined parameters & $0.062 / 0.052$ & $0.057 / 0.068$ \\
$R / w R$ & 2.15 & 1.85 \\
$S$ & $-0.47 / 0.33$ & $-0.45 / 0.54$ \\
\hline
\end{tabular}

The unit cell of the lattice of a monoclinic modification of a 5P single crystal at room temperature contains 15 crystallographically independent carbon atoms. At the stage of refining the coordinates and thermal parameters of atoms in the anisotropic approximation, maps of difference syntheses of electron density in the vicinity of carbon atoms were constructed and analyzed. The residual electron density peaks corresponding to 11 hydrogen atoms were revealed. The thermal parameters of hydrogen atoms were refined in the isotropic approximation of displacement atoms. The structure model, consisting of 26 independent atoms, is presented in two projections in Figure 4. It should be noted that, in 1988 [33], the unit cell parameters of a 5P single crystal were obtained at temperatures of $298 \mathrm{~K}$ and $110 \mathrm{~K}$, and in 1993 [34] the same authors studied their structure at the room temperature. The data on the lattice parameters and the model of the structure at the room temperature obtained in this work are consistent with the published data. As for the data on the lattice parameters of a 5P single crystal at the low temperature, in this work, in contrast to the literature data, a deviation of the unit cell angles from $90^{\circ}$ is revealed that exceeds the measurement error (Table 1). Thus, the structure of the p-quinquephenyl single crystal at $85 \mathrm{~K}$ was resolved in the P-1 space group. The unit cell of the lattice of the triclinic modification of the 5P single crystal at $85 \mathrm{~K}$ contains 120 crystallographically independent carbon atoms (Figure 5). In the crystal structure at the room temperature, the molecules have an almost flat conformation (the torsion angles between the phenyl groups does not exceed $1.4^{\circ}$ ) (Figure $4 \mathrm{~b}$ ).

In the low-temperature crystalline modification, the conformation of the molecules is not flat (Figure 5b,c). A model of the molecular structure in the crystal at $85 \mathrm{~K}$ with the value of the torsion angles between the phenyl groups is presented in Figure 5c. A similar feature of the conformational structure of the molecule-conjugated core at $293 \mathrm{~K}$ and $85 \mathrm{~K}$ is also inherent to the p-terphenyl and p-quaterphenyl crystals studied previously [18,32]. 

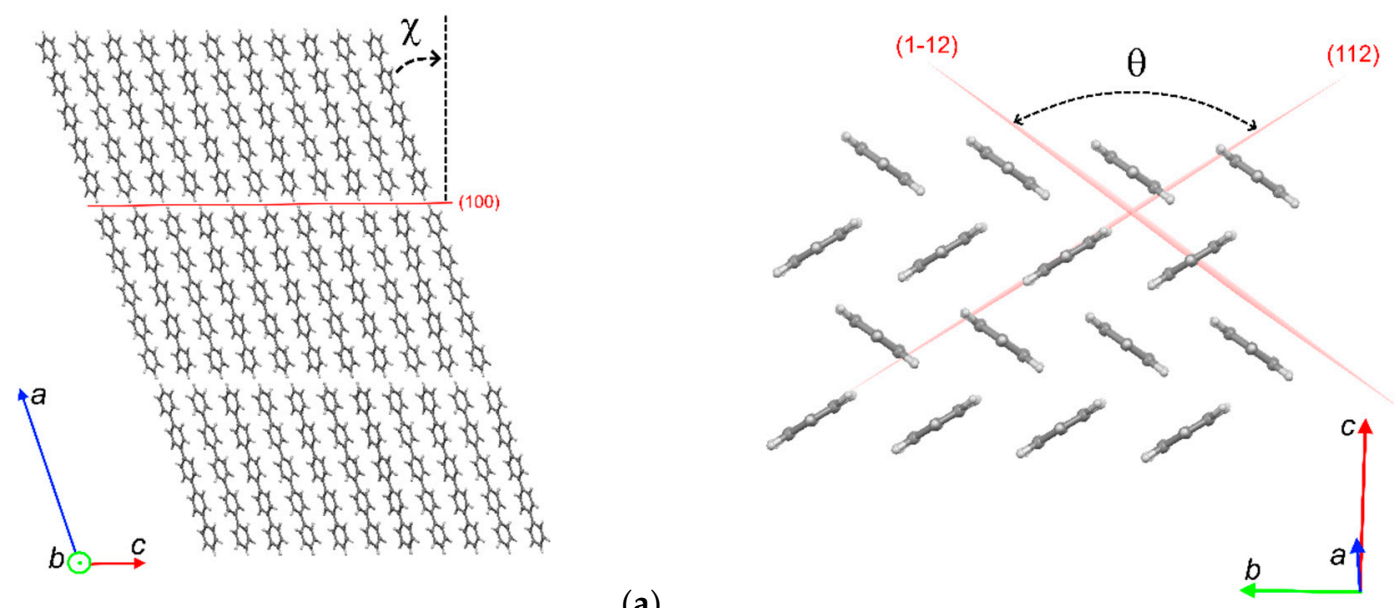

(a)

(b)

Figure 4. Crystal structure of p-quinquephenyl at $293 \mathrm{~K}$ : projections onto the planes (010) (a) and (100) (b).

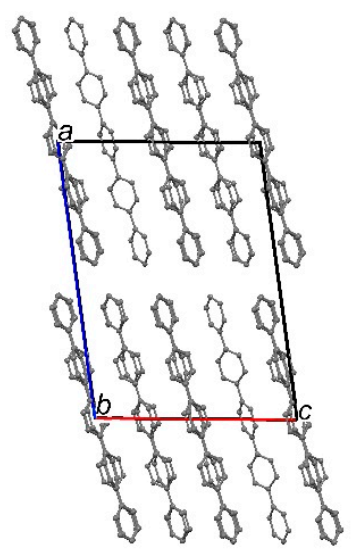

(a)

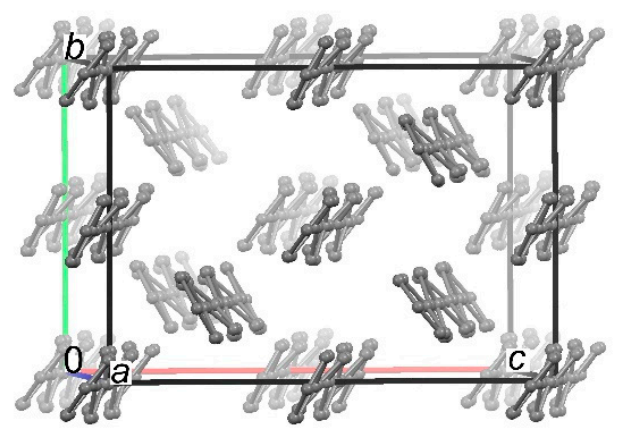

(b)

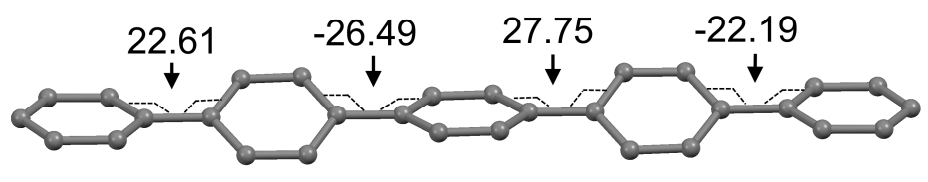

(c)

Figure 5. Crystal structure of p-quinquephenyl at $85 \mathrm{~K}:(\mathbf{a}, \mathbf{b})$ the unit cell projections onto the planes (010) (a) and (100) (b) (dark molecules in the upper layer, light molecules in the lower layer); (c) a conformation of the molecule in the crystal with the values of torsion angles between the phenyl rings.

Free-standing vapor-grown 5P single-crystalline films were convoluted due to their low thickness, which is a negative factor for obtaining high-quality results of a single crystal X-ray diffraction experiment. The structure of the large-area crystals grown by PVT was studied using a Miniflex 600 powder X-ray diffractometer. For the X-ray structural study, the crystals were laminated on a quartz substrate (Figure 3a,b). Figure 6 above shows a typical X-ray diffraction pattern for one of 
the crystals (black line). The calculated XRD powder pattern obtained from SCXRD data (CIF S1 in Supplementary Materials) is shown below in this image for comparison. As can seen, the diffraction pattern of single-crystalline film is a set of narrow peaks, the position of the first five of which is a multiple of the angles $2 \theta \approx 4.06^{\circ}$. This corresponds to the reflection from the (h00) planes for the crystal structure of 5P at room temperature (Table 1, CIF S1 in Supplementary Materials). Thus, the structure of $5 \mathrm{P}$ crystals grown from vapor is identical to the structure of $5 \mathrm{P}$ crystals grown from solution.

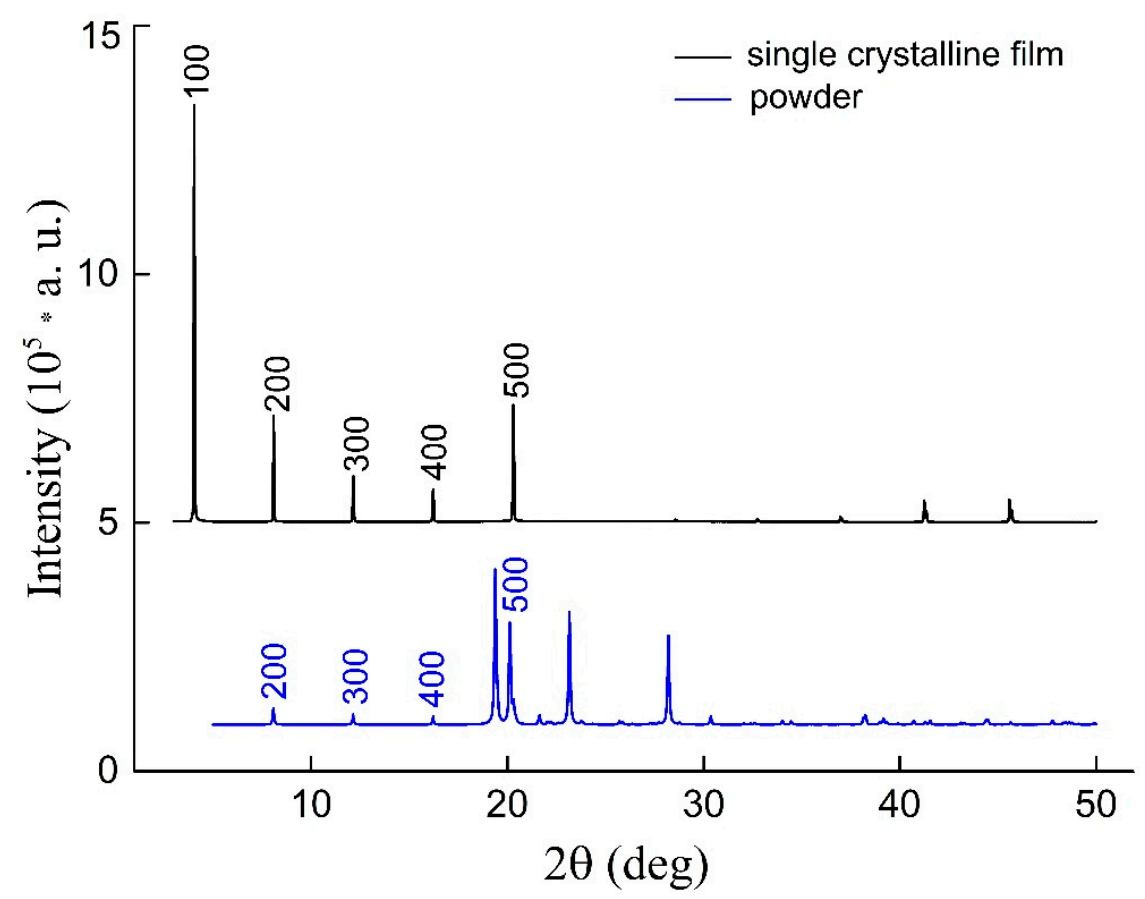

Figure 6. Diffraction patterns of a p-quinquephenyl vapor-grown single-crystalline film (black line) and crystalline powder (blue line).

Let us consider the crystalline packing of p-quinquiphenyl molecules in a crystal at $293 \mathrm{~K}$. The crystals of linear oligophenyls, including 5P, are characterized by a layered structure in the form of a stack of parallel equivalent monomolecular layers in the (100) orientation (Figure 4a). Lateral intermolecular interactions between the nearest molecules in the (100) layer are the strongest, and the end interactions between the molecules in neighboring monolayers are the weakest. Although the face (100) has the highest reticular density $\mathrm{N}_{100}=4.44 \times 1018 \mathrm{~m}^{-2}$, it is characterized by the lowest surface energy. Therefore, it is the most developed one among the other crystal faces due to the Gibbs-Curie-Wulf principle [18,32,35]. Inside the monolayer (100), the molecules are tilted relative to the normal to the plane at an angle $\chi=14.76^{\circ}$ (Figure $4 \mathrm{a}$ ) and packed in a herringbone order (Figure $4 \mathrm{~b}$ ). The densest rows of the equivalently spaced molecules are oriented along the [010] direction (Figure 4b). Among the faces characterized by lateral intermolecular bonds, the (011) face has the highest reticular density $\mathrm{N}_{011}=0.933 \times 10^{18} \mathrm{~m}^{-2}$, and the faces (001) and (010)- $\mathrm{N}_{001}=0.820 \times 10^{18} \mathrm{~m}^{-2}$ and $\mathrm{N}_{010}=$ $0.567 \times 10^{18} \mathrm{~m}^{-2}$, respectively. In the [001] and [010] directions, the molecules in adjacent rows are not in the equivalent positions-they are rotated relative to each other by a herringbone angle $\theta=110.97^{\circ}$. In the crystal lattice, two subsystems of the molecules can be distinguished, in each of which the plane of the molecule is parallel to either of the planes, (112) or (1-12), which intersect at an angle $\theta$ (Figure 4b).

\subsection{Photophysical Properties}

Figure 7 shows the PL spectra of 5P single crystals with a thickness d of 0.2 to $2 \mu \mathrm{m}$. A well-defined vibrational structure is observed for all these luminescence spectra. The maxima of the electron- 
vibrational bands correspond to the following wavelengths: $406 \mathrm{~nm}, 430 \mathrm{~nm}, 459 \mathrm{~nm}$ (shoulder), $488 \mathrm{~nm}$ (shoulder) [36].

As the thickness of the crystal decreases, an additional peak appears at the short-wave edge of the PL spectrum. Its intensity increases with decreasing crystal thickness (Figure 7). This peak refers to the suppressed self-absorption in the crystal (reabsorption) of 0-0 transition in the 5P molecule. Points on Figure 7 shows a possible view of the unreabsorbed PL spectrum of the crystal obtained by calculation using Expression (1):

$$
\mathrm{I}_{\mathrm{R} \neq 0}(\lambda)=\mathrm{I}_{\mathrm{R}=0}(\lambda) \times 10^{-\mathrm{A}(\lambda)}
$$

where $I_{R \neq 0}(\lambda)$ is the spectral dependence of the measured photoluminescence; $I_{R=0}(\lambda)$ is the calculated PL spectrum; $\mathrm{A}(\lambda)$ is the absorption spectrum of the crystal.

The spectral distribution $D(\lambda)=A(\lambda)+r(\lambda)+d(\lambda)$, obtained on the spectrophotometer, differs from the true absorption $A(\lambda)$. These differences are due to a large contribution to the attenuation of the parallel beam of probing radiation of reflection-r $(\lambda)$ and scattering- $d(\lambda)$ of light. These factors have less influence on the spectral distribution of the luminescence excitation. In the wavelength range of 360-410 $\mathrm{nm}$ (the edge of the absorption band with $\mathrm{D}(\lambda)<1$ ), the luminescence excitation spectrum practically does not differ from the true absorption of $A(\lambda)$. In this regard, the spectral dependence was approximated by the luminescence excitation spectrum of the $\mathrm{d} 4$ crystal when registering at a wavelength of $430 \mathrm{~nm}$ (Figure 7).

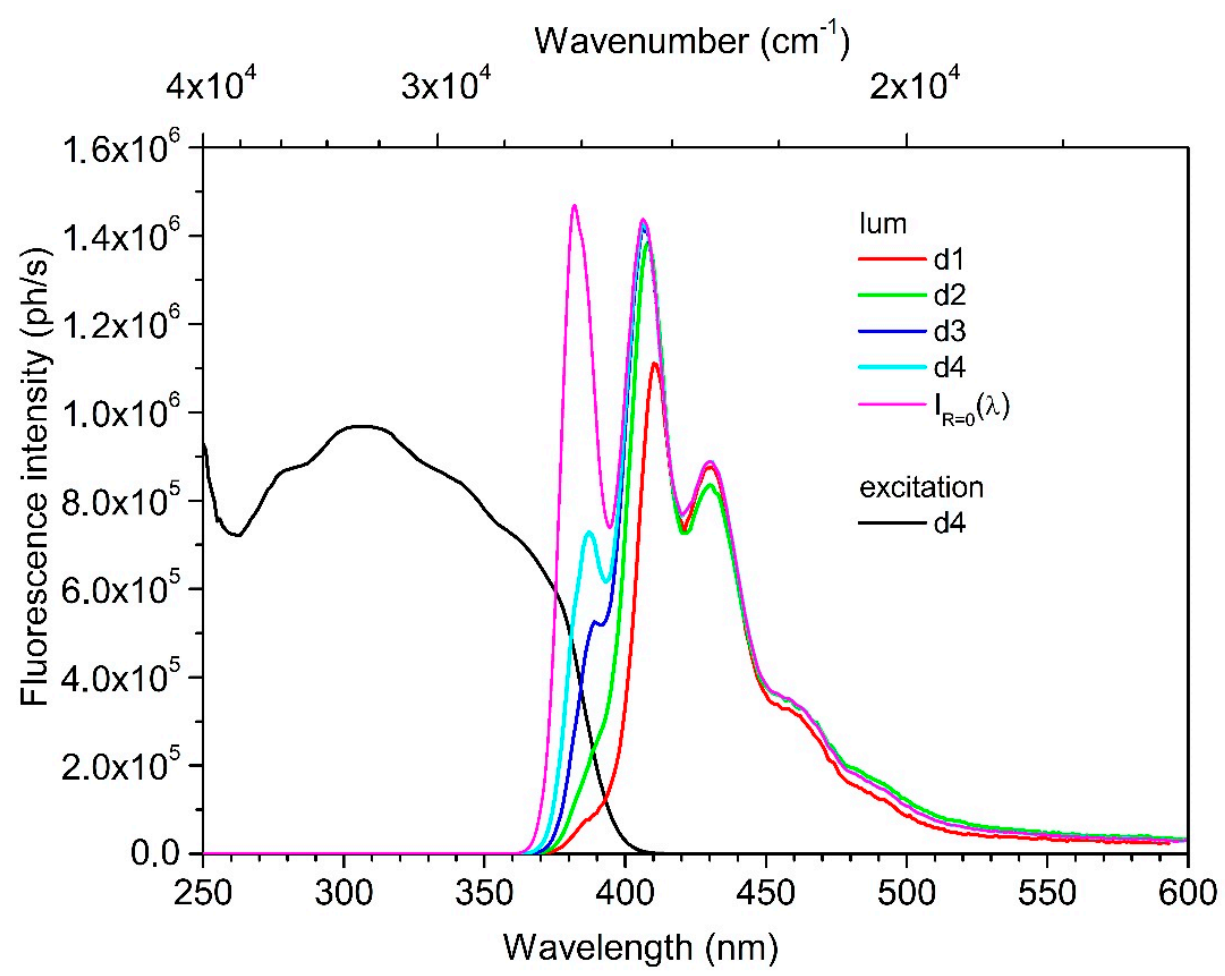

Figure 7. PL spectra of p-quinquephenyl crystals with different thicknesses $d(d 1>d 2>d 3>d 4)$ and the calculated spectrum without reabsorption $\mathrm{I}_{\mathrm{R}=0}(\lambda)$. The excitation wavelength was $325 \mathrm{~nm}$. The luminescence excitation spectrum of the $\mathrm{d} 4$ crystal is shown by black solid line (the luminescence registration wavelength was $430 \mathrm{~nm}$ ).

As can be seen from Figure 7, at room temperature in the true PL spectrum of a 5P molecule in a crystal, in addition to the bands mentioned above, there is also a band of $382 \mathrm{~nm}$.

Figure 8 shows the absorption and PL spectra of 5P solutions in hexane and THF, as well as the calculated PL spectrum $I_{R=0}(\lambda)$ of the crystal. Table 2 shows the $0-0$ transition positions for $5 \mathrm{P}$ in the 
crystal and in the solutions (hexane, THF, DMF), as well as the $0-0$ transition shift relative to the crystal $\left(\Delta \mathrm{E}_{0-0}\right)$.

As can be seen, transition from the crystal to the solution leads to a hypsochromic shift of the absorption and PL bands. The greater the hypsochromic shift observed, the lower the solvent polarity is. In the transition from the crystal to DMF and THF solutions, the values of the hypsochromic shift are $0.23-0.25 \mathrm{eV}$, and to hexane solution $0.42 \mathrm{eV}$. As the hypsochromic shift increases, the PL quantum yield decreases from 0.95 for a crystal to 0.63 for a solution in hexane (Table 2).

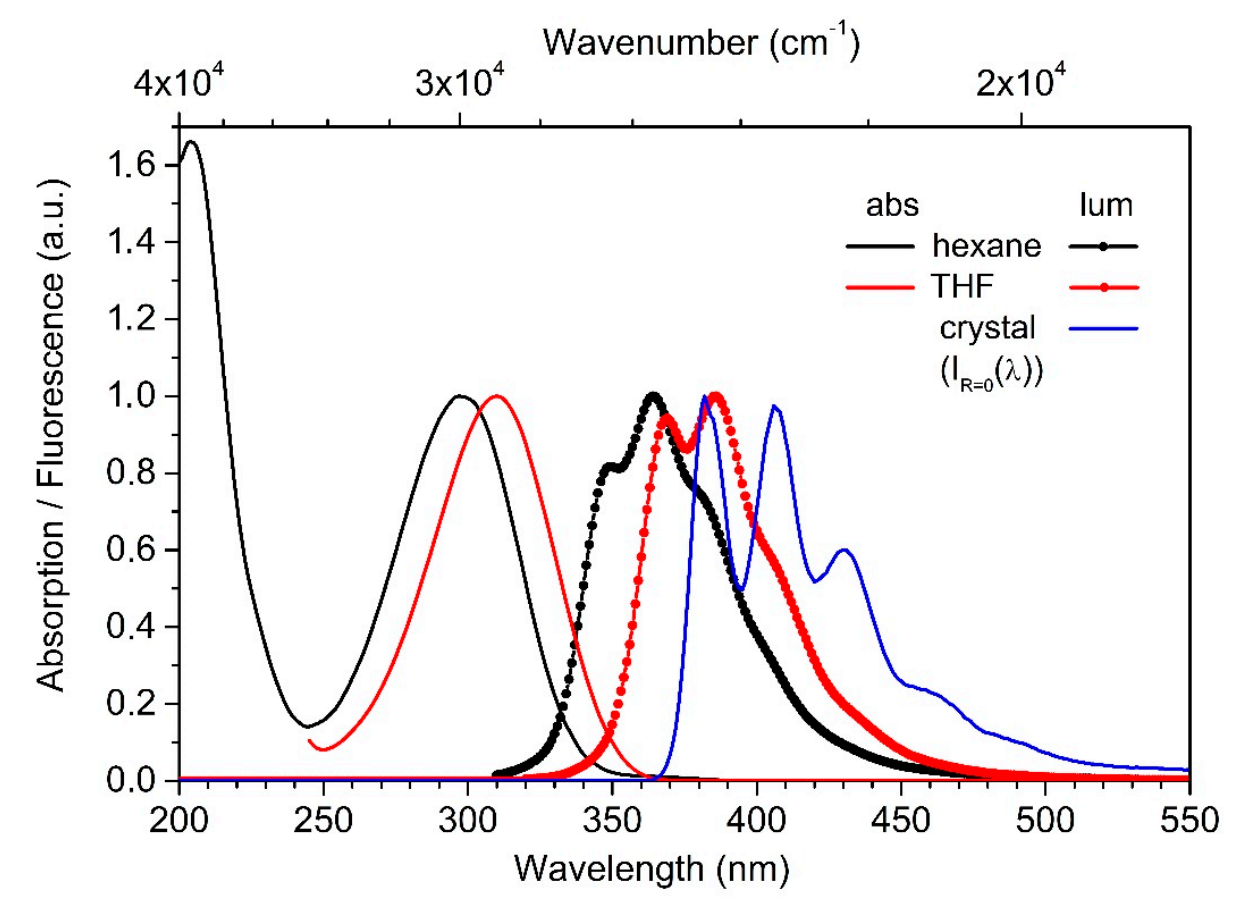

Figure 8. Normalized absorption and PL spectra of p-quinquephenyl in the solutions of hexane and THF. The calculated luminescence spectrum of the crystal without reabsorption $I_{R=0}(\lambda)$.

Table 2. The position of $0-0$ transition and the PL quantum yield of p-quinquephenyl in the crystal and diluted solutions.

\begin{tabular}{|c|c|c|c|}
\hline & $\begin{array}{c}\mathrm{E}_{0-0} \\
\mathrm{eV} / \mathrm{cm}^{-1}\end{array}$ & $\begin{array}{c}\Delta \mathrm{E}_{0-0} \\
\mathrm{eV} / \mathrm{cm}^{-1}\end{array}$ & PLQY \\
\hline crystal & $3.31 / 26,700$ & - & 0.95 \\
\hline $\mathrm{DMF}^{*)}$ & $3.54 / 28,500$ & $0.23 / 1800$ & 0.89 \\
\hline THF & $3.56 / 28,700$ & $0.25 / 2000$ & 0.93 \\
\hline hexan & $3.73 / 30,100$ & $0.42 / 3400$ & 0.63 \\
\hline
\end{tabular}

\section{Discussion}

The studies reported have shown that $5 \mathrm{P}$ molecules can be crystallized either from the solution or from the vapor phase in the form of large-area free-standing single-crystalline films. In general, for a family of linear oligophenyls, due to their uniform crystal structure, two-dimensional anisotropy of the crystal growth is an inherent quality $[18,32,35,38]$. It is worth noting that under the conditions of a slow growth from a hot chlorobenzene solution, faceted crystalline films with a higher surface morphological quality were obtained (the average linear growth rate of the films was $\mathrm{V}_{\mathrm{gr}} \approx 0.5 \mathrm{~mm} /$ day) (Figure 2) than those grown in a shorter time under the PVT method (Figure 3) with a temperature gradient in the growth zone of about $4 \mathrm{~K} / \mathrm{cm}$ (Figure 1) (the average linear growth rate of the films $\mathrm{V}_{\mathrm{gr}}$ 
was $\approx 2.5 \mathrm{~mm} /$ day). The growth anisotropy value, expressed as a ratio of the length 1 to the thickness $\mathrm{h}$ of the largest crystal samples, is ten times higher for the crystals grown from vapor under the less equilibrium conditions $\left(1 / \mathrm{h} \sim 5.10 \times 10^{3}\right)$ than those grown from the solution $(1 / \mathrm{h} \sim 100-200)$. This can be explained by the fact that the thermal velocity of translational and rotational motion of $5 \mathrm{P}$ molecules in the vapor phase is many times higher than it is in a dense solution medium. For this reason, it is assumed that the probability of capture of the 5P molecule by the adsorption layer on the low-energy surface of the face (100) will be significantly lower in comparison with the lateral faces ((001), (010), (011)) due to a shorter interaction period in collisions than in a viscous solution environment. The large-area free-standing single-crystalline films of 5P obtained from the solution can be easily transferred onto a substrate. Thus, organic optoelectronic devices, for example, field-effect or light-emitting transistors, can be developed on their basis.

It is rather simple to determine the relationship between the packing geometry of the molecules and the habitus of the crystals grown from the solution (Figure $2 b, c)$. As mentioned above, the surface of the monomolecular layer (100) is characterized by the lowest surface energy, which thus determines the main plane of the pinacoid (Figure 9a). It is possible to match the facet shape of a flat crystal with internal angles of $69^{\circ}$ and $111^{\circ}$, shown in Figure 9a, with a geometric prototype composed of a compact molecular cluster in (100) monolayer, bounded by the planes (011) and (0-11) (Figure 9b). As can be seen in Figure 9b, the outer contour of the molecular cluster thus selected, with an equal number of molecules in the length of the sides, is a rhombus with internal angles of $69.32^{\circ}$ and $110.68^{\circ}$. Thus, in quasi-equilibrium conditions of the growth from a solution, the peculiarity of the crystal packaging of the molecules causes the face shape of the crystals in the form of a thin rhombic film or plate.

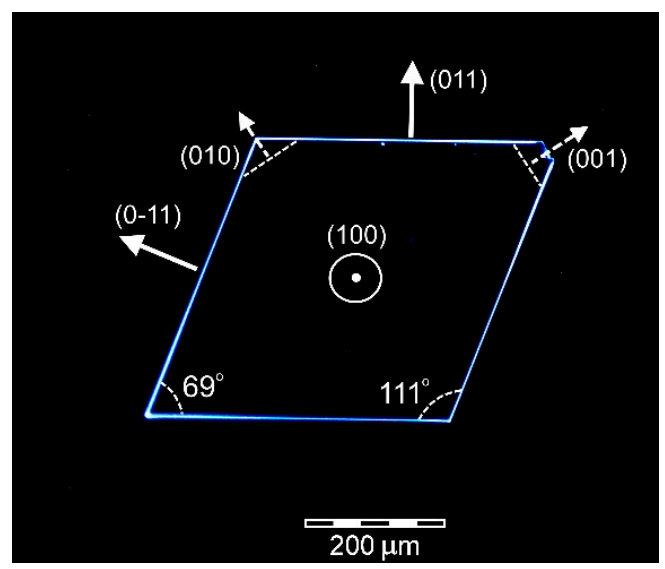

(a)

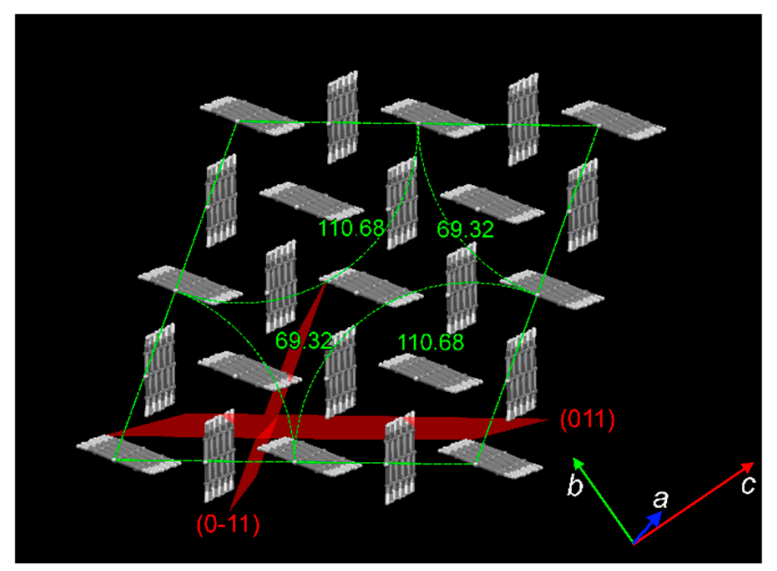

(b)

Figure 9. (a) Image of p-quinquephenyl single crystal under UV light with schematic representation of the growth directions and (b) schematic representation of a compact rhombic molecular cluster in a (100) layer.

The effect of the solvent polarity on the value of the hypsochromic shift of the absorption and PL bands of p-quinquephenyl relative to the crystal spectra is called a positive solvatochromic effect [39]. It can be assumed that the effect observed is due to the influence of the environment on the configuration of 5P molecules. It is known that rotation of the phenyl ring around a single $C-C^{\prime}$ bond in oligophenyls leads to a hypochromic effect, and the highest PLQY occurs with a planar configuration $[40,41]$. According to the X-ray diffraction data described above, 5P molecules in the crystal at the room temperature have an almost flat conformation (the torsion angle between the phenyl groups does not exceed $1.4^{\circ}$ ). Apparently, after their transition to the solution, the steric difficulties are partially removed, and the phenyl rings start rotating around the single $\mathrm{C}-\mathrm{C}^{\prime}$ bond, which leads to a hypsochromic shift of their optical spectra. In polar solvents (DMF, THF), rotation of the rings around the $\mathrm{C}^{\prime}-\mathrm{C}$ bond is "defrosted" to a lesser extent than in a non-polar hexane. The "blurring" of the clear 
electron-vibrational structure of the crystal luminescence after the transition to solutions is caused by the presence of molecules with different conformations in the solution. A similar behavior of the PL spectra was observed in [18] for p-terphenyl and its trimethylsilyl derivative.

\section{Conclusions}

In this work, large-area free-standing single-crystalline films of p-quinquephenyl were grown using the growth methods from solution and PVT. They crystal structure and optical properties were investigated. The crystal samples grown by the slow cooling of a hot solution of chlorobenzene for 32 days were noticeably superior in thickness and quality of the surface morphology as compared to the crystals grown under the PVT conditions for 3 days. The structure of the solution-grown p-quinquephenyl single crystals at the room temperature and at $85 \mathrm{~K}$ was studied using single crystal $\mathrm{X}$-ray diffraction. The data on the lattice parameters and the structure model at the room temperature were consistent with the literature data [33,34]. However, the structure of p-quinquephenyl single crystals at $85 \mathrm{~K}$ was for the first time solved in the space group $\mathrm{P}-1$. In the crystalline state at the room temperature, a conformation of the molecules is close to a flat one, while at the low temperatures, phenyl groups in the structure of the molecule are significantly deployed relative to each other (Figure 5). Different conformational states of p-quinquephenyl molecules, apparently, are the reason for the positive solvatochromic effect observed. It was found that, as the hypsochromic shift increases, the PL quantum yield decreases from 0.95 for a crystal to 0.63 for a solution in hexane. Investigation of the optical properties of 5P single-crystalline films of different thicknesses, 0.2 to $2 \mu \mathrm{m}$, made it possible to calculate their PL spectrum without reabsorption, which hides the shortest PL band at $382 \mathrm{~nm}$. High-quality large-area solution-grown crystals of p-quinquephenyl can be easily transferred onto a substrate for the purpose of further development of organic optoelectronic devices based on them.

Supplementary Materials: The following are available online at http://www.mdpi.com/2073-4352/10/5/363/s1, Video S1: Large 5P crystals in a chlorobenzene solution inside the growth vial; CIF S1: Crystal structure of 5P at 295 K; CIF S2: Crystal structure of 5P at $85 \mathrm{~K}$.

Author Contributions: Conceptualization and writing-original draft preparation, V.A.P.; methodology, O.V.B., N.I.S., E.A.S., N.M.S. and V.A.P.; synthesis, O.V.B., S.A.P.; crystal growth, M.S.L., A.A.K., V.A.P.; SCXRD, N.I.S.; powder XRD, A.A.K.; optical research, E.A.S., N.M.S.; writing-review and editing, V.A.P., M.S.L., N.I.S., A.E.V., O.V.B., E.A.S., N.M.S. and S.A.P. All authors have read and agreed to the published version of the manuscript.

Funding: Studies in part on p-quinquephenyl crystals growth from solution and crystal structure were made with financial support from the Ministry of Science and Higher Education of the Russian Federation within the State assignment FSRC "Crystallography and Photonics" RAS using the equipment of Collaborative Access Center "Structural diagnostics of materials" (project \# RFMEF162119X0035); studies in part on p-quinquephenyl crystals growth by the PVT method and their crystal structure were made under the support of the Russian Foundation for Basic Research (grant no. 19-32-90145); development of the approaches to purification of the conjugated oligomers was supported by the Russian Science Foundation (grant no. 18-73-10182); UV/Vis spectroscopy and fluorescence measurements were performed with the financial support from the Ministry of Science and Higher Education of the Russian Federation, using the equipment of the Collaborative Access Center "Center for Polymer Research" of ISPM RAS.

Conflicts of Interest: The authors declare no conflict of interest.

\section{References}

1. De Boer, R.W.I.; Gershenson, M.E.; Morpurgo, A.F.; Podzorov, V. Organic single-crystal field-effect transistors. Phys. Stat. Sol. 2004, 201, 1302-1331. [CrossRef]

2. Reese, C.; Bao, Z. Organic single-crystal field-effect transistors. Materialstoday 2007, 10, 20-27. [CrossRef]

3. Hasegawa, T.; Takeya, J. Organic field-effect transistors using single crystals. Sci. Technol. Adv. Mater. 2009, 10, 024314. [CrossRef] [PubMed]

4. Jiang, L.; Dong, H.; Hu, W. Organic single crystal field-effect transistors: Advances and perspectives. J. Mater. Chem. 2010, 20, 4994-5007. [CrossRef]

5. Muccini, M. A bright future for organic field-effect transistors. Nat. Mater. 2006, 5, 605-613. [CrossRef] [PubMed] 
6. Inada, Y.; Yamao, T.; Inada, M.; Itami, T.; Hotta, S. Giant organic single-crystals of a thiophene/phenylene co-oligomer toward device applications. Synth. Met. 2011, 161, 1869-1877. [CrossRef]

7. Hotta, S.; Yamao, T.; Zulkarnaen Bisri, S.Z.; Takenobu, T.; Iwasa, Y. Organic single-crystal light-emitting field-effect transistors. J. Mater. Chem. C 2014, 2, 965-980. [CrossRef]

8. Zeb, M.; Tahir, M.; Muhammad, F.; Said, S.M.; Sabri, M.F.M.; Sarker, M.R.; Ali, S.H.M.d.; Wahab, F. Amplified Spontaneous Emission and Optical Gain in Organic Single Crystal Quinquethiophene. Crystals 2019, 9, 609. [CrossRef]

9. Piaggi, A.; Lanzani, G.; Bongiovanni, G.; Mura, A.; Graupner, W.; Meghdadi, F.; Leising, G.; Nisoli, M. Emission properties of para-hexaphenyl polycrystalline films. Phys. Rev. B 1997, 56, 10133. [CrossRef]

10. Gundlach, D.J.; Lin, Y.-Y.; Jackson, T.N. Oligophenyl-based organic thin film transistors. Appl. Phys. Lett. 1997, 71, 3853. [CrossRef]

11. Huang, G.; Zhong, G.-H.; Wang, R.-S.; Hand, J.-X.; Lind, H.-Q.; Chen, X.-J. Superconductivity and phase stability of potassium-doped p-quinquephenyl. Carbon 2019, 143, 837-843. [CrossRef]

12. Hosoi, Y.; Koch, N.; Sakurai, Y.; Ishii, H.; Kampen, T.U.; Salvan, G.; Zahn, D.R.T.; Leising, G.; Ouchi, Y.; Seki, K. Structural study of thin films of neutral and potassium-doped oligophenylenes on Cu. Surf. Sci. 2005, 589, 19-31. [CrossRef]

13. Kintzel, E.J., Jr.; Smilgies, D.-M.; Skofronick, J.G.; Safron, S.A.; Van Winkl, D.H. Ultrathin film growth of p-phenylene oligomers on alkali halide substrates. J. Cryst. Growth 2006, 289, 345-350. [CrossRef]

14. Resel, R.; Koini, M.; Novak, J.; Berkebile, S.; Koller, G.; Ramsey, M. Epitaxial Order Driven by Surface Corrugation: Quinquephenyl Crystals on a $\mathrm{Cu}(110)-(2 \times 1)$ O Surface. Crystals 2019, 9, 373. [CrossRef]

15. Birks, B. The Theory and Practice of Scintillation Counting, 1st ed.; Pergamon Press Ltd.: Oxford, UK, 1964; p. 684. [CrossRef]

16. Higashino, T.; Akiyama, Y.; Kojima, H.; Kawamoto, T.; Mori, T. Organic Semiconductors and Conductors with tert-Butyl Substituents. Crystals 2012, 2, 1222-1238. [CrossRef]

17. Postnikov, V.A.; Odarchenko, Y.; Iovlev, A.V.; Bruevich, V.V.; Pereverzev, A.Y.; Kudryashova, L.G.; Sobornov, V.V.; Vidal, L.; Chernyshov, D.; Luponosov, Y.N.; et al. Molecularly Smooth Single-Crystalline Films of Thiophene-Phenylene Co-Oligomers Grown at the Gas-Liquid Interface. Cryst. Growth Des. 2014, 14, 1726. [CrossRef]

18. Postnikov, V.A.; Sorokina, N.I.; Alekseeva, O.A.; Kulishov, A.A.; Sokolnikov, R.I.; Lyasnikova, M.S.; Grebenev, V.V.; Borshchev, O.V.; Skorotecky, M.S.; Surin, N.M.; et al. Growth from Solutions, Structure, and Photoluminescence of Single-Crystal Plates of p-Terphenyl and Its Trimethylsilyl Derivative. Crystallogr. Rep. 2018, 63, 819. [CrossRef]

19. Postnikov, V.A.; Lyasnikova, M.S.; Kulishov, A.A.; Grebenev, V.V.; Borshchev, O.V. Solubility and Crystal Growth of p-Quaterphenyl and Its Derivative with Trimethylsilyl Terminal Substituents. Rus. J. Phys. Chem. A 2019, 93, 1741-1746. [CrossRef]

20. Postnikov, V.A.; Sorokina, N.I.; Kulishov, A.A.; Lyasnikova, M.S.; Grebenev, V.V.; Voloshin, A.E.; Borshchev, O.V.; Skorotetcky, M.S.; Surin, N.M.; Svidchenko, E.A.; et al. Highly luminescent crystals of a novel linear $\pi$-conjugated thiophene-phenylene co-oligomer with a benzothiadiazole fragment. Acta Cryst. B 2019, B75, 1076-1085. [CrossRef]

21. Laudise, R.A.; Kloc, C.; Simpkins, P.G.; Siegrist, T. Physical vapor growth of organic semiconductors. J. Cryst. Growth 1998, 187, 449. [CrossRef]

22. Jo, S.; Takenaga, M. Morphologies of Pentacene Crystals Obtained by Physical Vapor Growth Technique. Jpn. J. Appl. Phys. 2010, 49, 078002. [CrossRef]

23. Wang, H.; Zhao, Y.; Xie, Z.; Wang, H.; Wanga, B.; Ma, Y. The thermodynamic characteristics of organic crystal growth by physical vapor transport: Towards high-quality and color-tunable crystal preparation. CrystEngComm 2014, 16, 4539. [CrossRef]

24. Lopez-Romero, J.M.; Rico, R.; Martınez-Mallorquin, R.; Hierrezuelo, J.; Guillen, E.; Cai, C.; Otero, J.C.; Lopez-Tocon, I. Synthesis of penta-p-phenylenes with oligo(ethylene glycol) side chains. Tetrahedron Lett. 2007, 48, 6075. [CrossRef]

25. CrysAlis Pro Software System, Version 1.171.39.46; Rigaku Corporation: Oxford, UK, 2018.

26. Petricek, V.; Dusek, M.; Palatinus, L. Crystallographic Computing System JANA2006, General features. Z. Kristallogr. 2014, 229, 345. [CrossRef] 
27. Palatinus, L. Ab initio determination of incommensurately modulated structures by charge flipping in superspace. Acta Cryst. 2004, A60, 604. [CrossRef]

28. Shumilkina, E.A.; Borshchev, O.V.; Ponomarenko, S.A.; Surin, N.M.; Pleshkova, A.P.; Muzafarov, A.M. Synthesis and optical properties of linear and branched bithienylsilanes. Mendeleev Commun. 2007, 17, 34-36. [CrossRef]

29. Berlman, I.B. Handbook of Fluorescence Spectra of Aromatic Molecules; Academic Press: New York, NY, USA, 1971.

30. Lally, C.H.; Davies, G.J.; Jones, W.G.; Smith, N.J.T. UV quantum efficiencies of organic fluors. Nucl. Instrum. Methods Phys. Res. 1996, 117, 421. [CrossRef]

31. Ezhumalai, Y.; Wang, T.-H.; Hsu, H.-F. Regioselective Synthesis of Tetraphenyl-1,3-butadienes with Aggregation-Induced Emission. Org. Lett. 2015, 17, 536. [CrossRef]

32. Postnikov, V.A.; Sorokina, N.I.; Alekseeva, O.A.; Grebenev, V.V.; Lyasnikova, M.S.; Borshchev, O.V.; Surin, N.M.; Svidchenko, E.A.; Ponomarenko, S.A.; Voloshin, A.E. Growth from Solution, Structure, and Optical Properties of Single-Crystal para-Quaterphenyl Films. Crystallogr. Rep. 2018, 63, 139-148. [CrossRef]

33. Baker, K.N.; Knachel, H.C.; Fratini, A.V.; Adams, W.W. Structural transformations in crystalline oligomers of polyparaphenylene. Mat. Res. Soc. Symp. Proc. 1988, 134, 497-503. [CrossRef]

34. Baker, K.N.; Fratini, A.V.; Resch, T.; Knachel, H.C. Crystal structures, phase transitions and energy calculations of poly(p-phenylene) oligomers. Polymer 1993, 34, 1571. [CrossRef]

35. Postnikov, V.A.; Lyasnikova, M.S.; Kulishov, A.A.; Sorokina, N.I.; Voloshin, A.E.; Skorotetcky, M.S.; Borshchev, O.V.; Ponomarenko, S.A. Growth Anisotropy and Crystal Structure of Linear Conjugated Oligomers. Phys. Solid State 2019, 61, 2321. [CrossRef]

36. Taniguchi, M.; Lindsey, J.S. Database of absorption and fluorescence spectra of $>300$ common compounds for use in PhotochemCAD. Photochem. Photobiol. 2018, 94, 290. [CrossRef] [PubMed]

37. Seoul, C.; Song, W.-J.; Kang, G.-W.; Lee, C. Effect of molar mass on electroluminescence op poly(p-phenylene). Synth. Met. 2002, 130, 9. [CrossRef]

38. Postnikov, V.A. Formation and growth of biphenyl and naphthalene large single crystal sheets on liquid-air interface. Kondens. Sredy I Mezhfaznye Granitsy Condens. Matter Interphases 2013, 15, 160.

39. Nigam, S.; Rutan, S. Principles and Applications of Solvatochromism. Appl. Spectrosc. 2001, 55, 362A. [CrossRef]

40. Beale, R.N.; Roe, E.M.F. The Spectrophotometric Determination of Steric Hindrance in Some Stilbene Derivatives. J. Am. Chem. Soc. 1952, 74, 2302. [CrossRef]

41. Murrell, J.N. The Theory of the Electronic Spectra of Organic Molecules; John Wiley and Sons, Inc.: New York, NY, USA, 1963; p. 328. 